\title{
CAPITAL SOCIAL E \\ DESENVOLVIMENTO: \\ PERSPECTIVAS DE COMBATE \\ À POBREZA E DE \\ FORTALECIMENTO DAS \\ INSTITUIÇÕES DEMOCRÁTICAS
}

\author{
Andreia Maria Santiago \\ Aluna do curso de Direito da Unifor, orientada pela profa. dra. Mônica \\ Moita Tassigny \\ andreiamsantiago@gmail.com \\ monica.tass@gmail.com
}

Sumário: Introdução. 1. Globalização e pobreza nos países periféricos. 2. Aspectos teóricos do capital social. 3. Perspectivas de desenvolvimento e fortalecimento das instituições democráticas. Conclusão. Referências.

Resumo: Na atual conjuntura geopolítica internacional ainda não se concretizou uma política de combate à pobreza, principalmente nos países mais afetados pelas agruras sociais. Tal quadro reflete a crise das instituições democráticas que, em decorrência da falta de políticas públicas eficazes, torna os cidadãos descrentes com a governança. Este trabalho de natureza bibliográfica analisou como a dinâmica de formação e inserção do capital social no seio da coletividade auxilia na construção de uma consciência cívica e no estabelecimento de políticas públicas eficazes no combate à pobreza.

Palavras-chave: Capital social. Desenvolvimento social. Instituições democráticas.

\section{INTRODUÇÃO}

O modelo neoliberal apresentado na década de 1980, baseado nas recomendações do Consenso de Washington, não resultou no esperado no que se refere ao combate à pobreza.

A dinâmica desse modelo acoplada com a era da globalização tem demonstrado que mesmo nos países em desenvolvimento, onde foram adotadas as diretrizes neoliberais, destarte pudessem constatar um razoável crescimento econômico, os problemas sociais persistiram e aprofundaram-se. Ficou notório 
que o crescimento econômico não implica necessariamente na melhoria do bemestar da população como um todo, acentuando-se as enormes disparidades na distribuição de renda.

Nesse cenário de conservação da pobreza, em que as pessoas têm como maior preocupação a garantia de sua sobrevivência cotidiana, há, na maioria das vezes, um afastamento da arena política. Isso porque preocupações mais amplas e de certa forma consideradas mais complexas passam a ser postergadas. Rompe-se, assim, o elo entre Estado e sociedade e ampliam-se as incertezas quanto ao futuro da nação e, consequentemente, estrutura-se um ambiente de pleno descrédito com a política, comprometendo, dessa forma, o processo de fortalecimento democrático.

Ante essa realidade, o presente artigo visa demonstrar como a criação de mecanismos que favorecem a formação de redes de integração pode contribuir para a modificação desse quadro. Apresenta-se o conceito de capital social como um instrumento de coesão e de inspiração na formação de ideais de cooperação mútua e de solidariedade com vistas à redução da pobreza.

Tratou-se de pesquisa bibliográfica: no primeiro momento, traçou-se um panorama da realidade político-econômica em que se encontra a sociedade mundial, demonstrando alguns fatores que influenciam no crescimento das disparidades sociais e na proliferação da pobreza. Autores como Amartya Sen (1999) e Marcello Baquero (2007) forneceram as argumentações teóricas.

No segundo, abordou-se a conceituação teórica de capital social, adentrando nas dimensões que lhe foram atribuídas por Robert D. Putnam (1995). Apresenta-se também fatores considerados por Neto e Froes (2002) como determinantes para a sua formação e consolidação.

Por fim, traçou-se um paralelo entre o desenvolvimento e o fortalecimento das instituições democráticas, tentando demonstrar como o empoderamento dos cidadãos e seu enquadramento no cenário político reflete na operacionalização de políticas públicas com vistas à redução da pobreza.

\section{Globalização e Pobreza nos Países Periféricos ${ }^{1}$}

É incontestável o alto nível de pobreza que assola grande parte da humanidade, principalmente nos países periféricos que contam com histórico de dominação econômica, agravado ainda mais na década de 1980, quando se inseriu na conjuntura internacional um novo modelo de capitalismo, ligado à era da globalização, conhecido por neoliberalismo.

\footnotetext{
${ }^{1}$ Consideram-se países periféricos aqueles que têm um menor grau de desenvolvimento e que estão localizados na África, na América Central e no Oriente Médio.
} 
Esse novo sistema foi desenvolvido pelas Nações Unidas, como bem esclarece Chomsky (2002, p. 21-22):

O termo neoliberalismo sugere um sistema de princípios que, ao mesmo tempo que é novo, baseia-se em ideias liberais clássicas [....]. Esse sistema doutrinário é também conhecido como Consenso de Washington, expressão que sugere algo a respeito da ordem global. [....]

O Consenso [neoliberal] de Washington é um conjunto de princípios orientados para o mercado, traçados pelo governo dos Estados Unidos e pelas instituições financeiras internacionais que ele controla e por eles mesmos implementados de formas diversas - geralmente, nas sociedades mais vulneráveis, como rígidos programas de ajuste estrutural.

Segundo Milton Friedman (1984), um dos inspiradores do neoliberalismo, a doutrina neoliberal tem como características a mínima intervenção do Estado na economia, a abertura do mercado para a entrada das multinacionais, a livre circulação de capitais internacionais com ênfase na globalização e a política de privatização das empresas estatais, sendo a base da economia formada por empresas privadas.

Dentro do atual contexto mundial de aplicabilidade desses princípios neoliberais, percebe-se que esse modelo agravou problemas estruturais da sociedade, impossibilitando as pequenas economias de se desenvolverem em bases nacionais, aumentando as desigualdades e contribuindo para a exacerbação da pobreza, em suma, acentuando a exclusão social.

Nessa linha de expansão capitalista e crescimento do comércio global, bem assevera Muhammad Yunus (2008, p.18):

[...] nem todos estão se beneficiando. A própria distribuição de renda global expõe os fatos: $94 \%$ da renda mundial vai para $40 \%$ da população, ao passo que os $60 \%$ têm de viver com somente $6 \%$ da mesma renda. Assim, metade da população mundial vive com cerca de dois dólares por dia, enquanto quase um bilhão de pessoas vivem com menos de um dólar por dia.

Considerando que o neoliberalismo patrocina o acúmulo de riquezas nas mãos de uma minoria, como bem demonstrado anteriormente, é fácil compreender como esse modelo contribui para uma desestruturação das relações de convivência social, dissolvendo entre as pessoas valores de confiança recíproca e de solidariedade.

Não obstante as grandes disparidades sociais acentuadas por tal modelo, este contexto propicia uma desilusão coletiva em relação à gestão dos governantes, fazendo que os cidadãos não acreditem no modus operandi da política como forma de equacionar as mazelas sociais. Assim, uma das consequências é o 
descrédito nas instituições políticas, acarretando um desengajamento da sociedade civil do cenário político, enfraquecendo os regimes democráticos (BAQUERO; CREMONESE, 2006).

A reflexão sobre esse quadro demonstra o quanto é necessário e urgente buscar mecanismos que solucionem, ou pelo menos reduzam, os problemas sociais contemporâneos, principalmente, o da pobreza nos países periféricos. Nessa empreitada é que se apresentam as posteriores considerações sobre um dos instrumentos aptos a auxiliar na solução dessa problemática, qual seja: o capital social.

\section{Aspectos Teóricos do Capital Social}

A temática do capital social vem ganhando espaço significativo no mundo acadêmico, sobretudo no âmbito das ciências sociais. Apesar de sua importância e da vasta literatura já existente sobre o assunto, ainda não há um consenso sobre o conceito de capital social.

De acordo com Coleman (1988, p.96), o capital social pode ser definido como um conjunto de:

[.... normas, confiança interpessoal, redes sociais e organização social [....], importantes no funcionamento, não apenas da sociedade, mas também da economia, configurando-se uma coligação de relações sociais e de recursos acessíveis.

$\mathrm{O}$ autor supracitado entende que o capital social deve ser entendido de forma funcional, ou como um recurso para os indivíduos que estão inseridos em uma dada estrutura econômica, social e política, possibilitando aos membros satisfazerem seus objetivos. Segundo ele, são os aspectos desta estrutura que facilitam certas ações comuns dos agentes sociais.

Outro teórico de grande destaque na tratativa do tema é Robert D. Putnam (2007), responsável pela popularização do termo capital social, dando a ele visibilidade internacional após a publicação, em 1993, da obra Making democracy work: civic traditions in modern Italy, quando apresenta ao mundo seus estudos nas regiões da Itália, objetivando a exploração de questões fundamentais da vida cívica e sua relação causal com o desempenho institucional. Dessa forma define capital social: “(...) o capital social diz respeito a características da organização social, como confiança, normas e sistemas, que contribuam para aumentar a eficiência da sociedade, facilitando as ações coordenadas" (2007, p. 177).

Seus estudos demonstram que o capital social possui uma natureza multidimensional, assim, à medida que as redes vão se formando e se ampliando, passa-se de um patamar para outro, o que Putnam (apud MARTELETO E SILVA) classificou como as três dimensões essenciais do capital social. 
A primeira dimensão é conhecida como capital social de ligação (redes Bonding), nessa dimensão as redes formam-se entre pessoas muitas próximas, seja por laços de parentesco, de amizade ou de etnia. Por terem características semelhantes, elas resolvem agruparem-se, no intuito de desenvolverem mecanismos de cooperação que facilitem a vida de todo o grupo. Nesse sentido dispõem Marteleto e Silva (2004, p. 44):

O capital social possui uma natureza multidimensional. A visão mais estreita o define como um conjunto de normas e redes sociais que afetam o bemestar da comunidade na qual estão inscritas, facilitando a cooperação entre os seus membros pela diminuição do custo de se obter e processar informação. Nesse caso, as relações de base para a formação das redes seriam entre iguais, isto é, entre indivíduos similares do ponto de vista de suas características demográficas.

A segunda dimensão é a do capital social de ponte (redes Bridging). Ela consiste na ampliação das redes Bonding, rompendo fronteiras e fazendo pontes com outras comunidades distintas, ligadas nesse nível não mais por laços fortes de amizade, mas pela busca de objetivos comuns, conservando a horizontalidade das relações. A formação dessas teias possibilita um acesso a novas estruturas que aumentam o alcance das ações.

$\mathrm{Na}$ terceira dimensão, capital social de conexão (redes linking), a formação de redes se dá por conexão das comunidades às instituições de poder, na qual as pessoas se unem, objetivando alavancar recursos para o desenvolvimento das comunidades. Assim, quando as comunidades agem conjuntamente ganham maior força para pressionar a governança a disponibilizar os recursos para atender às demandas locais.

Compreender teoricamente essas dimensões do capital social requer uma profunda análise em redes já formadas, haja vista que conseguir efetivá-las pressupõe muito mais que vontade. Exige, primeiramente, a concepção na comunidade, mesmo que intuitivamente, do espírito de virtude cívica, pois há uma forte relação entre comprometimento cívico e desenvolvimento de uma região, nessa linha teoriza Putnam (2007, p. 30-31): “[....] a comunidade cívica se caracteriza por cidadãos atuantes e imbuídos de espírito público, por relações políticas igualitárias, por estrutura social firmada na confiança e na colaboração".

Posto isso, e depois de pontuadas as dimensões do capital social, é importante relatar quais são as condições que antecedem e propiciam a sua implementação.

Segundo Neto e Froes (2002), são três essas condições: a primeira, diz respeito à ampliação social da cooperação, ocorrendo pela formação de comportamentos altruístas que estimulam sentimentos de solidariedade, bem como pela criação de cooperativas institucionais que priorizam formas horizontais de 
gestão; a segunda, ao fomento de novas parcerias com vista ao envolvimento de empresas, governo e entidades do terceiro setor, objetivando entradas para o desenvolvimento técnico e proliferação de capital; a terceira, à criação de redes que o autor define como "arranjos institucionais inovadores".

Conforme esses autores, além dessas condições propícias, elencaram cinco fatores determinantes na formação do capital social: organização, confiança, iniciativa, solidariedade social e participação.

Feitas essas considerações teóricas, é importante ponderar que a análise da dinâmica de formação do capital social não se encerra nos modelos apresentados, mesmo porque a temática do capital social ainda está em construção. Contudo, esses modelos servem de referencial para se extrair conceitos importantes na compreensão de como se formam essas redes de integração.

\section{Perspectivas de Desenvolvimento e Fortalecimento das InSTITUIÇÕes Democráticas}

Ao falar-se em redução da pobreza, não há como não vinculá-la ao desenvolvimento local de uma dada região. Mas é importante ponderar que esse desenvolvimento não deve está vinculado apenas ao viés econômico, pois nem sempre que se tem crescimento econômico, tem-se uma melhoria na condição socioeconômica das pessoas menos favorecidas.

Nessa perspectiva é que o conceito de desenvolvimento local se sustenta na ideia de que as localidades devem dispor de recursos econômicos, humanos, institucionais, ambientais e culturais, nessa linha dispõe Sen (2000, p. 29):

O desenvolvimento tem de estar relacionado, sobretudo com a melhoria da vida que levamos e das liberdades que desfrutamos. Expandir as liberdades que temos razão para valorizar não só torna nossa vida mais rica e mais desimpedida, mas também permite que sejamos seres sociais mais completos, pondo em prática nossas volições, interagindo com o mundo em que vivemos influenciando esse mundo.

Assim, a noção de desenvolvimento local encerra em um conjunto de valores, princípios e métodos, profundamente inovadores, através da utilização de práticas radicalmente diferentes das utilizadas, fazendo interagir práticas setoriais em busca de objetivos comuns que visem o desenvolvimento interno de um dado local.

Para Boisier (2000, p. 166), o desenvolvimento local é:

Um processo de crescimento econômico e de câmbio estrutural que conduz a uma melhoria no nível da qualidade de vida da população local, no 
qual se pode identificar três dimensões: uma econômica, em que os empresários locais usam sua capacidade para organizar os fatores produtivos suficientes para ser competitivos nos mercados; outra, sociocultural, em que os valores e as instituições servem de base ao processo de desenvolvimento; e, finalmente, uma dimensão político-administrativa em que as políticas territoriais permitem criar um entorno econômico local favorável, protegendo de interferências externas e impulsionando o desenvolvimento local.

Essa prática de desenvolvimento local funcionaria como um exercício dinâmico de cooperação, envolvendo fatores sociais, culturais e políticos que não se regulam exclusivamente pelo sistema de mercado. Nessa forma de desenvolvimento, o crescimento econômico é variável essencial, porém não suficiente para ensejar desenvolvimento social.

Assim, para que o crescimento de uma região reflita em desenvolvimento social, é necessário que políticas públicas sejam estabelecidas no sentido de redistribuir renda. Portanto, salutar é a importância do Estado no estabelecimento de programas de governo que visem o bem-estar social, mas a adoção dessa prática por parte dos governantes tem-se demonstrado deficiente, fato que comprova a impotência das instituições tradicionais.

A democracia mostra a sua fragilidade em não conseguir agregar os interesses da sociedade, demonstrando a atual crise que perpassa as democracias. Nesse sentido, aborda Marcello Baquero, (2004, p. 265, 266):

[....] não só a precariedade da dimensão social torna imperativo pensar em outros modelos e estratégias de análise que proporcionem as bases de construção de uma sociedade plena, com acesso mínimo das pessoas aos bens materiais (moradia, habitação, saúde e educação), mas, sobretudo, a crescente desconexão que se estabeleceu entre o Estado e a sociedade. Tal situação de crise tem produzido a fragmentação e a atomização da sociedade brasileira, limitando severamente seu avanço como entidade autônoma, soberana e com poder de interferência nos negócios públicos.

Esse entendimento, apesar de referir-se à realidade brasileira, é perfeitamente aplicável a várias outras democracias, principalmente as dos países periféricos; refletindo a necessidade de se buscar novas soluções para a resolução das desigualdades sociais.

É dessa necessidade que desponta a importância do capital social que se apresenta, segundo os ensinamentos de Robert Putnam (2007), com algumas características inerentes à utilização de redes de integração como forma de resgatar a confiança e a utilização de normas baseadas em relações de reciprocidade, auxiliando a formação associativa como indutora da prática de atitudes que 
fomentem o espírito de cooperação e de solidariedade, fatores propícios para o desenvolvimento local.

Dessa forma, o fortalecimento democrático e o desenvolvimento de uma dada localidade caminham na mesma direção, por isso faz-se necessário o fortalecimento de ideais de confiança, de associativismo e de cooperação entre as pessoas, como uma alternativa capaz de fazer frente à crise de desconfiança nas instituições democráticas.

Nesse aspecto, deve-se promover o capital social como mediação do empoderamento dos cidadãos, fortalecendo o grau de consciência cívica da sociedade no sentido de estarem estimulados a desenvolverem ações que resultem no bem coletivo. Putnam (2007, p. 102) descreve aspectos de uma comunidade cívica que vem referendar esse pensamento:

Em muitos aspectos, os cidadãos de uma comunidade cívica são mais do que meramente atuantes, imbuídos de espírito público e iguais. Os cidadãos virtuosos são prestativos, respeitosos e confiantes uns com os outros, mesmo quando divergem em relação a assuntos importantes. A comunidade cívica não está livre de conflitos, pois seus cidadãos têm opiniões firmes sobre as questões públicas, mas são tolerantes com seus oponentes.

O grau de informação dos cidadãos é fundamental na hora de cobrar dos governantes um desempenho satisfatório. Assim, a participação política dos cidadãos torna-se uma condição imprescindível para um bom desenvolvimento local.

O grau de empoderamento político das pessoas, muitas vezes, aponta os caminhos do desenvolvimento. De modo mais especifico, pode-se afirmar que a participação dos cidadãos legitima a democracia e leva, de modo mais seguro, à redução das desigualdades sociais. Nessa linha, esclarece Putnam (2007, p. 103-104):

Diz-se que as associações civis contribuem para a eficácia e a estabilidade do governo democrático, não só por causa de seus efeitos 'internos' sobre o indivíduo, mas também por causa de seus efeitos 'externos' sobre a sociedade. No âmbito interno, as associações incutem em seus membros hábitos de cooperação, solidariedade e espírito público. [....]. No âmbito externo, a 'articulação de interesses' e a 'agregação de interesses', como chamam os cientistas políticos deste século, são intensificadas por uma densa rede de associações secundárias.

Assim, em sociedades em que o grau de consciência cívica é elevado tem-se maior força para o estabelecimento de mobilizações, para a liberalização de forças produtivas que visem por em prática um desenvolvimento com fundamento na ética e na sustentabilidade que tenha pôr escopo o bem-estar social. 
Nesse campo é que se pode utilizar o capital social como um instrumento de ligação das pessoas, como um meio de fazer surgir no seio da sociedade regras de reciprocidade e de participação cívica com vistas ao desenvolvimento local, promovendo, por fim, o fortalecimento das instituições democráticas.

\section{CAPITAL SOCIAL E APLICABILIDADE}

Dentro de uma apreciação do modus operandi de desenvolvimento e de expansão do capital social e baseado em relações de cooperação entre uma rede de pessoas, percebe-se que para a formação, implementação e um bom desempenho dessas redes, algumas ações poderiam ser tomadas como as indicadas abaixo:

A formação e execução de projetos pedagógicos, nas redes já existentes, com o intuito de auxiliá-las no crescimento e ampliação. Nessa perspectiva, associa-se as ideias de capital social à noção de cultura, esclarecendo Silva Junior (2007, p. 2): "certos padrões culturais possibilitam a fruição de práticas de reciprocidade e cooperação impactando diretamente no desenvolvimento econômico das nações".

Promoção pelas instituições de ensino de palestras nas comunidades de baixa renda e com pouca perspectiva de alcançar um emprego formal, com o intuito de mostrar para os integrantes dessas comunidades como unidas poderão desenvolver alguma atividade que gere renda. O ideal seria que a instituição, além de incentivar o trabalho coletivo, demonstrasse para as comunidades quais são os serviços mais procurados no entorno delas e como elas poderiam se organizar para oferecer tal serviço. Tassigny (2008, p. 97): "La Dimensión Democrática tiene como objetivo el fortalecimiento de la ciudadanía, favoreciendo el acceso a las oportunidades de trabajo, por medio de la oferta de cursos de formación profesional'.

O empoderamento das pessoas, principalmente nas comunidades mais vulneráveis, estabelecendo-se políticas públicas que visem o fortalecimento de sua autonomia, dando a elas perspectivas mais amplas de empreendedorismo, mostrando como há diversas formas de garantir uma existência digna. Conforme Silveira (2006, p. 252):

[.... a defesa da necessidade de fomentar a participação da cidadania se associa ao conceito de empoderamento. Este termo tem sido utilizado em vários países e por diversas áreas do conhecimento, mas, no que se refere a essa discussão, a sua aplicabilidade tem-se concentrado em como desencadear maior envolvimento dos indivíduos em ações cooperativas, solidárias e políticas, capacitando-os para se articularem em prol de interesses coletivos.

Por fim, o estabelecimento de colaborações mútuas entre Estado, setores privados e os mais diversos segmentos sociais, com o escopo de promover o pensamento cívico entre as pessoas, despertando no íntimo da sociedade sentimentos 
de solidariedade e responsabilidade social, instrumentos indispensáveis para um desenvolvimento baseado na ética e com vista à redução das mazelas sociais.

\section{Conclusão}

O presente artigo expôs o conceito de capital social, apresentando-o como um instrumento de auxílio no combate à pobreza e como um mecanismo de promoção do desenvolvimento local.

Nessa linha, demonstrou-se brevemente que a atual conjuntura neoliberal incentiva práticas comerciais voltadas apenas para o lucro, fato que repercute de modo negativo nos países periféricos, pois eleva o nível de desigualdade social, propiciando um enfraquecimento de valores de cooperação e solidariedade.

Nesse contexto, as instituições democráticas também perderam força, e cada vez que os governantes não conseguiam traçar políticas públicas eficazes de combate à pobreza, mais os cidadãos se afastavam do centro político, demonstrando uma grande desilusão com as referidas instituições.

É nesse cenário de plena crise das instituições que surge o capital social como um instrumento alternativo na solução desses problemas, por intermédio de suas características de formação de teias sociais integrativas que incitam a consolidação de ideais éticos voltados para a confiança e para solidariedade. Uma sociedade que tem em seu seio ideais consolidados e virtudes cívicas passa a participar mais ativamente da vida política, e a pressionar com mais ênfase seus governantes, resultando de forma reflexa na efetivação de políticas públicas e, por conseguinte, na redução da pobreza.

\section{REFERÊNCIAS}

BAQUERO, Marcelo (Org.). Capital Social, desenvolvimento sustentável e democracia na América Latina. Porto Alegre: UFRGS, 2007.

BAQUERO, Marcelo. Formas alternativas de participação política ou naturalização normativa? Cultura política e capital social no Brasil. Net, Florianópolis, out. 2004. Disponível em: < http://www.periodicos.ufsc.br/index. php/politica/article/viewFile/1984/1733>. Acesso em: 15 de mar. 2010.

BAQUERO, Marcelo; CREMONESE, Dejalma (orgs.). Capital social: teoria e prática. Ijuí: Editora Unijuí, 2006.

BOSIER, S. Desarrollo (local): ¿ Dé qué estamos hablando? In: BECKER, F; BANDEIRA, S.P. (Orgs). Determinantes e desafios contemporaneous. Santa Cruz do Sul: Edunisc, 2000. 
CASTRO, Maria Luiza A.C. A metodologia de redes como instrumento de compreensão do capital social. Disponível em: < http://br.monografias.com> . Acesso em: 18 de mar. 2010.

CHOMSKY, Noam. O lucro ou as pessoas: neoliberalismo e ordem global. Tradução de Pedro Jorgensen Jr. 3. Ed. Rio de Janeiro: Bertrand Brasil, 2002.

COSTA, Achyles Barcelos; COSTA, Beatriz Morem da. Cooperação e capital social em arranjos produtivos locais. Disponível em: $<$ www.anpec.org.br/ encontro2005/artigos/A05A113.pdf>. Acesso em 31 de mar. 2010.

CREMONESE, Dejalma. A contribuição do capital social na consolidação da democracia latino-americana. Disponível em: < http://br.monografias.com>. Acesso em: 22 de mar. 2010.

COLEMAN, James S. "Normas como o capital social". In: RADNITSKY, et al. Imperialismo econômico: o método econômico aplicado fora do campo da economia. New York: Paragon, 1987.

DAHL, A. Sobre a democracia. Tradução de Beatriz Sidou. Brasília : UNB, 2001.

DEUS, Maria Helena Botelho Moreira de. Formação de capital social em comunidade de baixa renda. Fortaleza: Unifor, 2008.

FRIEDMAN, Milton. Capitalismo e liberdade. São Paulo: Abril Cultural, 1984.

FRIEDMAN, Milton. Neoliberalismo. Disponível em : $<$ http://www.suapesquisa. com:geografia/neoliberalismo.htm>. Acesso em: 14 mar. 2010.

MARTELETO, Regina Maria; SILVA, Antonio Braz de Oliveira. Redes e capital social: o enfoque da informação para o desenvolvimento local. Ciência da Informação. Brasília, v.33, n.3, p. 41-49, set/dez. 2004.

MULS, Leonardo Marco. Desenvolvimento local, espaço e território: o conceito de capital social e a importância da formação de redes entre organismos e instituições locais. Disponível em: <www.anpec.org.br/revista/vol9/vo19n1p1_21. pdf $>$. Acesso em: 31 mar. 2010.

NETO, Francisco de Paulo; FROES, César. Empreendedorismo social: a transição para a sociedade sustentável. Rio de Janeiro: Qualitymark, 2002.

NETO, Francisco de Paulo; FROES, César. Gestão da responsabilidade social: o caso brasileiro. Rio de Janeiro: Qualitymark, 2001.

PUTNAM, Robert D. Comunidade e democracia: a experiência da Itália moderna. Tradução de Luiz Alberto Monjardim. Rio de Janeiro: Fundação Getúlio Vargas (FVG) 2007.

RATTNER, Henrique. Prioridade: construir o capital social. Disponível em: $<$ www.mundodigital.unesp.br/sulamerica/materias/6prioridadesconstruirocapit alsocial-henriquerattener.pdf $>$. Acesso em: 31 mar. 2010. 
SEN, Amartya Kumar. Desenvolvimento como liberdade. Tradução de Laura Teixeira Motta. São Paulo: Companhia das Letras, 2000.

SEN, Amartya Kumar. Sobre ética e economia. Trad. Laura Teixeira Motta. 7. ed. São Paulo: Companhia das Letras, 1999.

SILVA JÚNIOR, José Deocleciano de Siqueira. O Capital Social: discussão em torno da construção de um conceito. Disponível em: <http://www. espacoacademico.com.br_>. Acesso em: 22 mar. 2010.

SILVEIRA, Angelita Fialho. O empoderamento e a constituição de capital social entre a juventude. In: BAQUERO, Marcelo; CREMONESE, Dejalma (orgs.). Capital social: teoria e prática. Ijuí: Editora Unijuí, 2006, p.251-274.

STIGLITZ, Joseph E. A globalização e seus malefícios. Tradução de Bazán Tecnologia e Linguística. São Paulo: Futura, 2002.

TASSIGNY, Mônica. Extensión, ciudadanía e inclusión social: bases conceptuales y el programa de formación para el trabajo. In: Responsabilidad social de las universidades. Buenos Aires: Fundación Red Latinoamericana de Cooperación Universitaria (FRLCU), 2008, p. 86-101.

VIEIRA, Ciliane da Rosa; ALBERT, Carla Stefania; BAGOLIN, Izete Pengo. Crescimento e desenvolvimento econômico no Brasil: uma análise comparativa entre o PIB per capita e os níveis educacionais. Análise. Porto Alegre, V.19, n.1, p.28-50, jan./jun. 2008.

YUNUS, Muhammad. Um mundo sem pobreza: a empresa social e o futuro do capitalismo. Tradução de Juliana A. Saad e Henrique Amat Rêgo Monteiro. São Paulo: Ática, 2008.

\section{SOCIAL CAPITAL AND DEVELOPMENT: FIGHTING POVERTY AND STRENGTHENING DEMOCRATIC INSTITUTIONS}

Abstract: In the current geopolitical panorama, a successful policy to fight poverty has not been materialized yet. It lacks especially in countries that are more affected by disrupted social conditions. This framework reflects the crisis of democratic institutions that, due to the lack of effective public policy, makes citizens skeptical about governance. This work of bibliographical nature examines how the dynamics of training and integration of social capital within the community helps to build a civic consciousness and the establishment of effective public policies to fight poverty.

Keywords: Social capital. Social development. Democratic institutions.

Data de recebimento: jan/2011 - Data de aprovação: mar/2011 